\title{
URBANISATION IMPACT ON CREATION OF HEAT ISLANDS IN LARGE CITIES
}

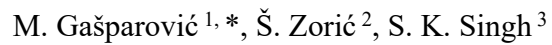 \\ ${ }^{1}$ Chair of Photogrammetry and Remote Sensing, Faculty of Geodesy, University of Zagreb, Kačićeva 26, Zagreb, Croatia - \\ mgasparovic@geof.unizg.hr \\ ${ }^{2}$ Geo Line Systems d.o.o., Svetog Križa 4, Split, Croatia - zoric.simun@gmail.com \\ ${ }^{3}$ K. Banerjee Centre of Atmospheric \& Ocean Studies, IIDS, Nehru Science Centre, University of Allahabad, Prayagraj-211002, \\ Uttar Pradesh, India - sudhirinjnu@gmail.com
}

Commission TS, WG III/7

KEY WORDS: Global warming, urbanisation, automatization, classification, urban heat island effect

\begin{abstract}
:
Global warming is getting more and more attention, and one of the main reasons is the rapid growth of the surface temperature. Today more than fifty percent of the human population is living in the cities, and with the growing tendency by the year 2050 to seventy percent, urbanisation is becoming one of the main factors of global warming. Conducted research indicates that the heat island effect is increasing rapidly in a territory with fast urbanisation growth. The surface temperature and air temperature are increasing in surrounding rural areas. This research aims to analyze urbanisation's impact on creating heat islands in a specific time frame from 1990 until 2020 in five large cities with satellite imagery obtained from Landsat satellite missions. By conducting the land cover classification and interpretation of vegetation indexes with the help of GEE (Google Earth Engine) and GIS tools as well as their changes in time by using different channels of satellite imagery will try to show the correlation between urbanisation and heat islands. This research is important for the professional and academic society because the control of global warming and increasing the quality of life in cities is today's priority.
\end{abstract}

\section{INTRODUCTION}

The land surface temperature (LST) is changing due to rapid growth of urban areas causing urban heat islands effect. More than fifty percent of the human population resides in the cities and with the growing tendency by the year 2050 to seventy percent. Urbanisation is becoming one of the main factors of global warming. Conducted research (Rajasekar and Weng, 2009; Gašparović et al. 2017; Gunawardena et al. 2017; Gašparović 2020) indicates that the heat island effect is increasing rapidly on a territory with fast urbanisation growth (Connolly et al. 2020). LST and air temperature are increasing in surrounding rural areas due to rise in urban infrastructure and loss of vegetation and water bodies. The Landsat satellite mission's data have been used to analyze the urbanisation impact on creating heat islands in large cities (Avdan and Jovanovska 2016). Conducting the land cover classification and interpretation of vegetation indexes and their time changes using different satellite imagery channels will show the correlation between urbanisation and heat islands (Ahmed et al. 2020).

The cities worldwide are experiencing a high increase in urban population. Therefore urbanisation becomes one of the major concerns of global warming, climate change and environmental issues. The regions reporting rapid urbanisation experience change in local climate, socio-economic disparity and environment due to the urban heat island effect (Chen et al. 2006). As in the urban area, a high rate of increase of impervious surface resulted in the change in land surface temperature hence urban areas experiencing high UHI effect (Kikon et al. 2016). Li and Zha (2019) carried out a study through ground-based observation and remote sensing data to measure the canopy layer heat islands effects (CLHIs) in 32 cities of China and investigated CLHIs relationships with nighttime lights, surface albedo, built-up intensity, vegetation activity and surface urban heat island intensity (SUHII). A study carried out in Shiraz city, Iran, employs the Landsat data and machine learning algorithms to understand UHI (Kamali Maskooni et al. 2021). The study results suggested that the mean LST increased due to a significant decrease in green spaces, increase in industrial units, and urbanisation.

Consequently, a substantial upward trend was displayed by the urban heat island ratio index (URI). The lack of vegetation cover in the urban areas shows that during the redevelopment plan of cities, it should be considered a significant amount of vegetation which can reduce heat stress (Renard et al. 2019). Ahmed et al. (2020) have found that due to afforestation and adoption of good management practice, the UHI effect can be minimized in urban areas.

This paper aims to present the urbanisation of several large cities and its impact on the land cover and provide a link between urbanisation and global warming, which is one of the burning issues of today and the issue of consensus. Relate to the phenomenon of global warming and how to reduce its impact and increase the quality of life while preserving the natural balance. A special emphasis will be placed on one segment of global warming: UHI. The UHI is an urban area that is significantly warmer than the surrounding rural areas and is mainly caused by human activity. Heat swelling is a phenomenon present in both summer and winter. The main causes are the higher density of houses and buildings, heat release by consuming fossil fuels, traffic, and natural ventilation reduction. Thermal islands also impact increasing energy consumption, thus contributing to the greenhouse gas effect and global warming. Although heat islands can occur in any area,

* Corresponding author 
they are more likely in the city because their surfaces tend to retain large amounts of heat. Some research suggests that heat islands affect global warming. According to the Environmental Protection Agency (EPA), the annual air temperature in a city with a population of one million maybe $1-3{ }^{\circ} \mathrm{C}$ higher than in an area outside the city. Thermal islands impact increasing energy consumption, increasing greenhouse gas emissions, water quality, and human health (Oldenborgh et al. 2018)

This research presents a methodology for testing the urbanisation impact on creating heat islands in large cities.

\section{MATERIALS AND METHODS}

\subsection{Study site and data}

The study site and analysis of urbanisation to create thermal islands will be some of the five world's megalopolises that are very interesting because they have the largest population overflow in a short period and, due to their size, are very specific for observing and performing analyses over the area. Cairo, Istanbul, Mexico City, Sao Paulo and Tokyo are taken as examples. Figure 1 shows the city of Cairo.

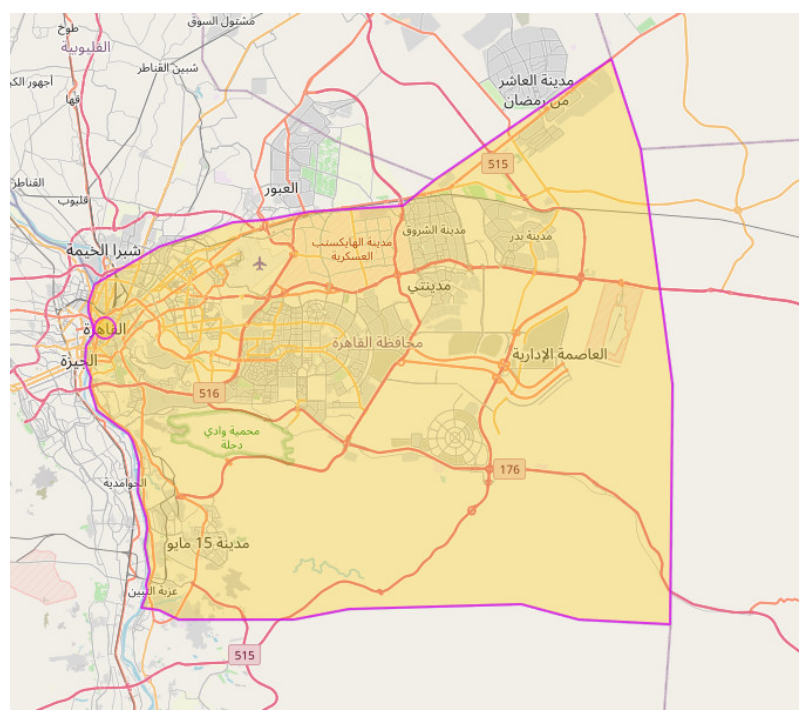

Figure 1. Cairo, one of the five study sites of this research.

For this research, imageries of the Landsat satellite mission have been used. The Landsat Mission founded back in 1972, is the longest series of launched satellites that record the Earth's surface. For more than four decades, medium-resolution data has been collected and stored and continuously provided insight into our planet's visual and scientific features. The mentioned period is long enough to assess trends and analyze changes on the Earth's surface. Thus, a unique historical archive was created, which stands out in terms of the number of details, quality and the included space-time segment. The mentioned base continuously provides insight into the visual and scientific features of our planet. The Landsat footage archive is often mentioned as one of humanity's greatest treasures, an achievement that brings great benefits to all segments of society.

One of the main goals of this research is to use the available software to speed up and simplify downloading large amounts of data for different areas of the Earth over 30 years or more (from 1990 to 2020). Thus, Google Earth Engine was used, a platform under the auspices of Google that allows users to analyze and visualize geospatial datasets (Gašparović and Singh 2020). Google Earth Engine contains data sets such as Landsat satellite missions, MODIS and Sentinel satellite missions that are available for fast downloading and processing at a global scale. The results of this research will give a new perspective on this problem. The paper will also conduct analyses that include the visualization of the dynamics of change, comparing different periods through confusion matrices, histograms, and images. The developed algorithm provides new knowledge that can be widely applied in various research mapping and monitoring urban heat islands in large cities. The developed algorithm can be used in many other areas around the Earth and based on the other satellite data.

This research is based on clear-sky Landsat 5, 7 and 8 data (Figure 2) to allow a large temporal overlap of satellite data with ground truth data. The atmospherically pre-corrected surface reflectance data were used from the Landsat 5 sensor (USGS Landsat 5 Surface Reflectance Tier 1). One of the used satellite in this research, Landsat 5 satellite data, contains seven bands: four visible and near-infrared (VNIR) bands, two shortwave infrared (SWIR) of 30-m spatial resolution, and one thermal infrared TIR band of 120-m spatial resolution (Table 1). Values for all used satellite imagery bands in this research (Landsat 5, Landsat 7 and Landsat 8) were extracted via Google Earth Engine.

\begin{tabular}{|c|c|c|}
\hline Band & Wavelength $(\mu \mathrm{m})$ & Description \\
\hline B1 & $0.45-0.52$ & Blue \\
B2 & $0.52-0.60$ & Green \\
B3 & $0.63-0.69$ & Red \\
B4 & $0.77-0.90$ & Near Infrared (NIR) \\
B5 & $1.55-1.75$ & Shortwave infrared 1 (SWIR) \\
B6 & $10.40-12.50$ & Thermal infrared \\
B7 & $2.09-2.35$ & Shortwave infrared 2 \\
\hline
\end{tabular}

Table 1. Spectral bands of the Landsat 5 imagery (Gašparović et al. 2017)

\subsection{Methods}

For testing urbanisation impact on the creation of heat islands in large cities, three different spectral indices were used: Normalized difference vegetation index (NDVI), Normalized Difference Built-up Index (NDBI) and Modified Normalized Difference Water Index (MNDWI). Calculation of indices mentioned above was done based on the following equations (13):

$$
\begin{gathered}
\text { NDVI }=\frac{\text { NIR }- \text { GREEN }}{\text { NIR+GREEN }} \\
\text { NDBI }=\frac{\text { SWIR }- \text { NIR }}{\text { SWIR+NIR }} \\
\text { NDVI }=\frac{\text { GREEN }- \text { SWIR }}{\text { GREEN+SWIR }}
\end{gathered}
$$

where NIR, GREEN and SWIR bands are defined in Table 1 for the Landsat 5 imagery. Accordingly, to the Landsat 7 and Landsat 8 bands' spectral characteristics, the same equations were used to calculate the spectral indices. The land surface temperature data was acquired based on the B6 for Landsat 5 and Landsat 7 imagery and B11 for Landsat 8 imagery.

\section{RESULTS}

Results for all study areas (Cairo, Istanbul, Mexico City, Sao Paulo, and Tokyo) are shown below in this section. Firstly, 
spatio-temporal data from 1990 to 2020 were acquired and spectral indices for each available satellite imagery for five megalopolises were calculated. The obtained results are prepared in the form of a graph where the relationship of different indices (Normal Difference Vegetation Index NDVI; Normalized Difference Build up Index - NDBI; Modified Normalized Difference Water Index - MNDWI) with the land surface temperature (LST) is shown. The linear trend of the measured indices and LST was calculated. Based on the trend, the good and bad types of urbanisation during the years can be determined. Cairo and Tokyo study areas are especially emphasized with detailed preliminary findings.
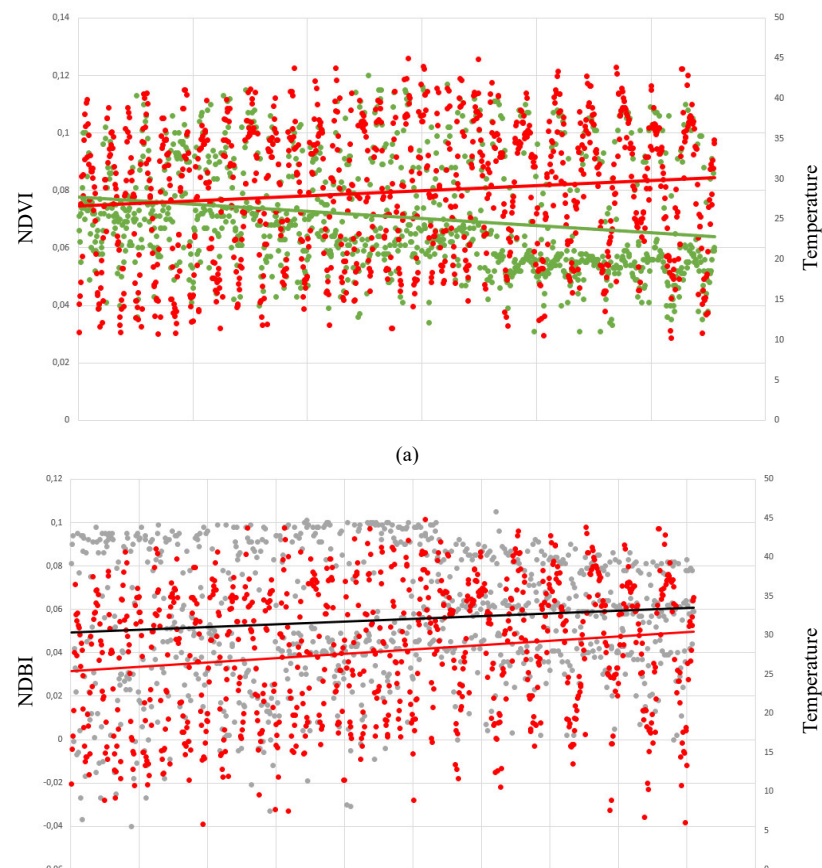

(b)

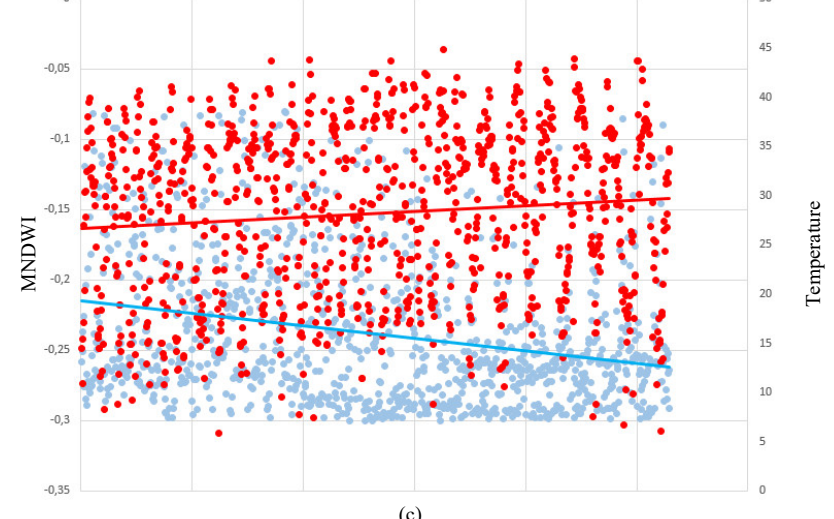

Figure 2. Statistical visualization of mean values acquired based on Landsat imagery during the 30 years for the city of Cairo. (a)

Relationship between temperature and NDVI, (b) the

relationship between temperature and NDBI and (c) the relationship between temperature and MNDWI.

For Cairo, from 1990 to 2020, we have LST increasing of almost $3^{\circ} \mathrm{C}$ and an NDVI decrease of nearly 0.02 (Fig. 2a). The correlation between temperature and NDBI is visible (Fig. 2b). Correlation emphasizes that urbanisation increasing led to increasing land surface temperatures in cities and the creation of UHIs. Figure $2 \mathrm{c}$ shows an inversely proportional change between the share of water in the city and temperature. For Cairo, during the increase in temperature, the share of greenery (NDVI) and share of water surfaces (MNDWI) were decreased, while the share of construction (NDBI) was increased. That clearly shows that urbanisation has a great impact on the creation of UHI in Cairo.
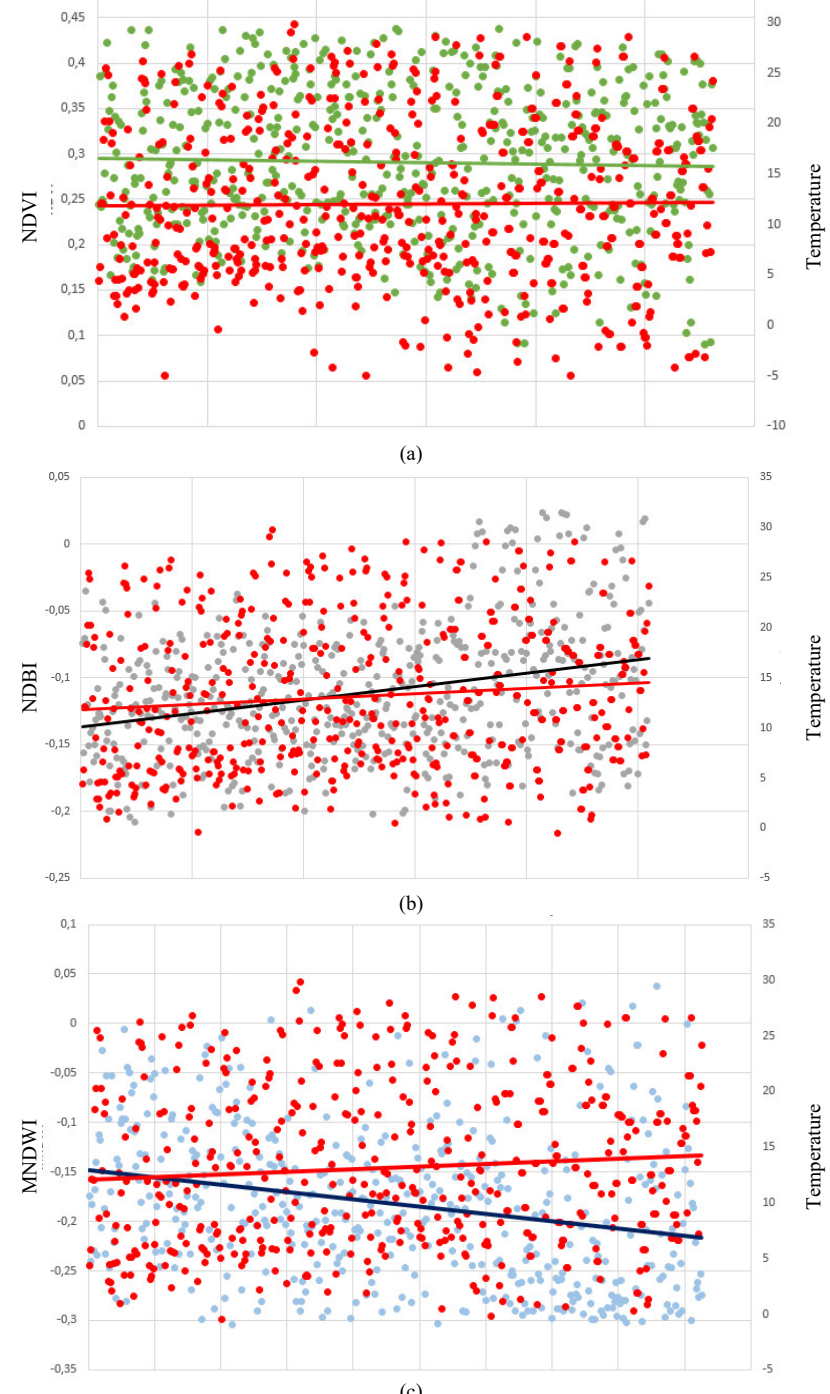

Figure 3. Statistical visualization of mean values acquired based on Landsat imagery during the 30 years for the city of Tokyo.

(a) Relationship between temperature and NDVI, (b) the relationship between temperature and NDBI and (c) the relationship between temperature and MNDWI.

For Tokyo, in the period from 1990 to 2020, a slight LST increase and slight NDVI decrease are observed (Fig. 3a). The growth of construction and built-up areas is not entirely proportional to the increase in temperature because it is visible a greater increase of construction than the increase in temperature in the city (Fig. 3b). Figure 3c shows how there has been an increased change in the MNDWI index, which shows us the presence of water surfaces in the city area concerning the temperature rising at a lower rate compared to the MNDWI. 
However, if the graphs in Figure $3 \mathrm{~b}$ and Figure $3 \mathrm{c}$ are compared, the proportion between NDBI and MNDWI tells us that certain water surfaces were drained or ameliorated to obtain a larger area used for construction. Below are shown land cover maps based on the supervised classification conducted in GEE. Land cover maps represent three main land cover classes important for the research: vegetation, water and built-up area.

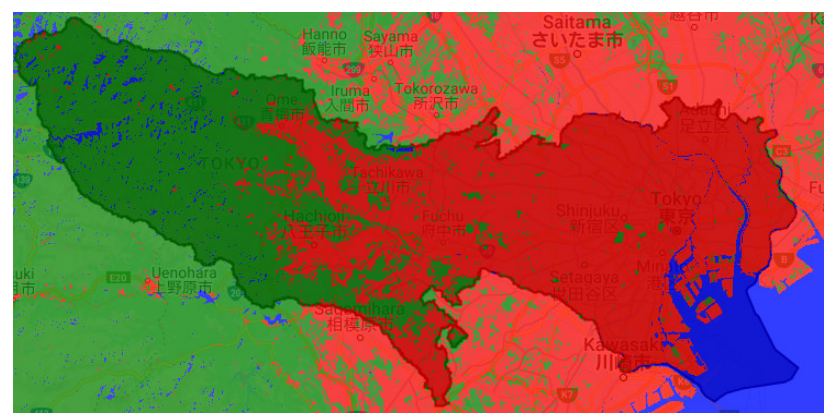

(a)

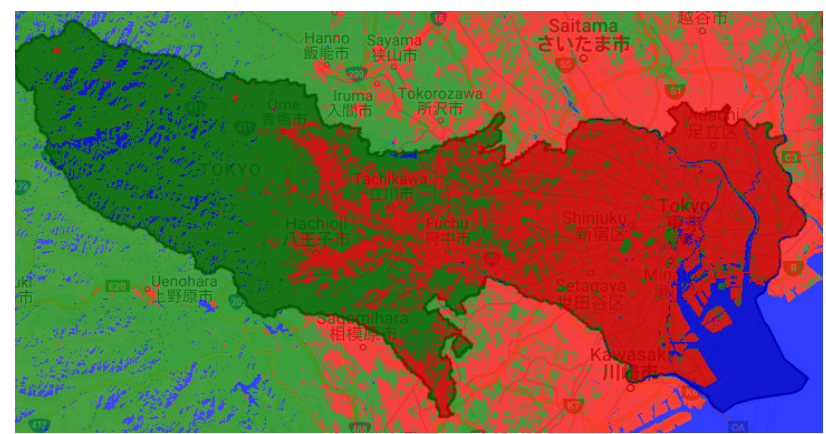

(b)

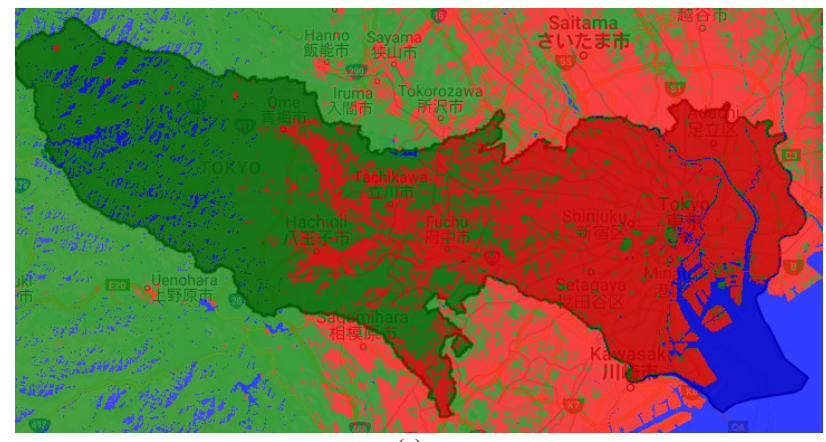

(c)

Figure 4. Land cover classification for Tokyo for years (a) 1990,

(b) 1999 and (c) 2020. The built-up area will be shown red, vegetation green, and water blue, respectively.

Figure 4 shows the potential reason for trends shown in Figure 3. The steep curve of MNDWI and NDBI is distinctly visible when looking at Figures $4 \mathrm{~b}$ and $4 \mathrm{c}$. That is the western part of the city of Tokyo, where the part of the city that was mostly underwater now forms a built-up area and the part under vegetation has been replaced by a built-up area. These changes in land cover are clearly shown in Figure 3.

Further in the text will be shown results for Mexico City (Fig. 5), Sao Paolo (Fig. 6) and Istanbul (Fig. 7).

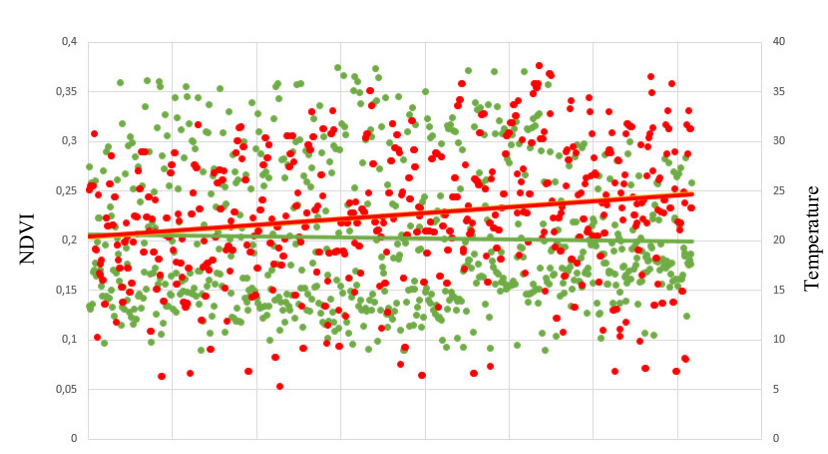

(a)
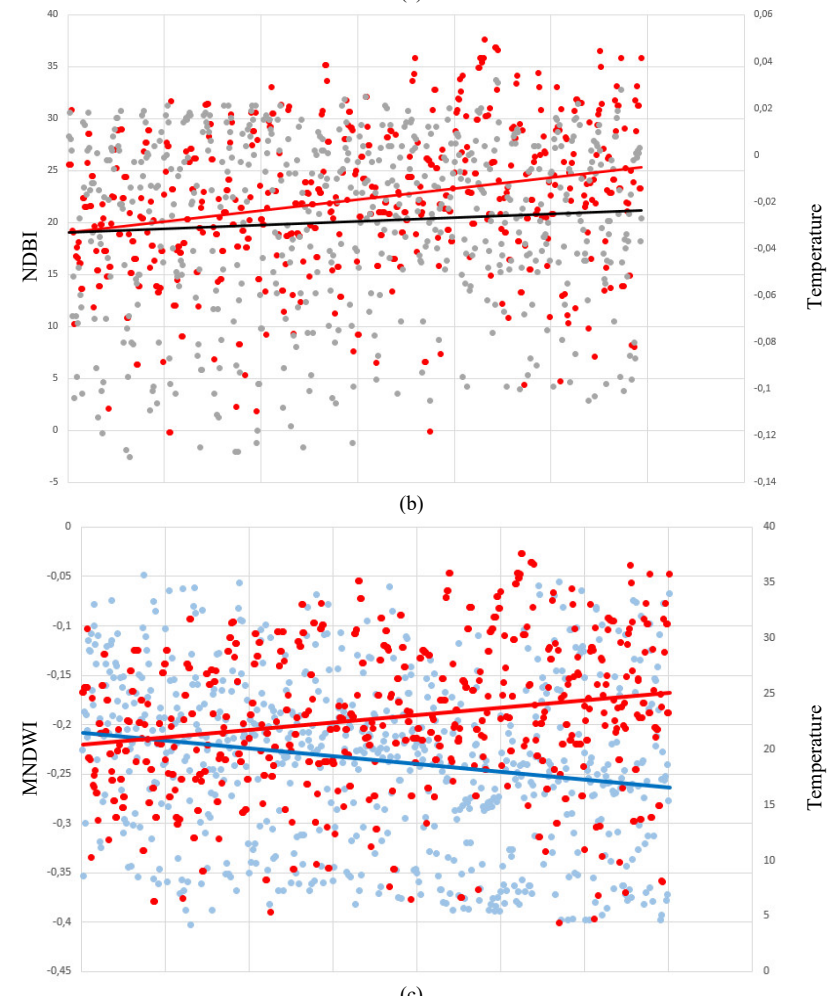

(c)

Figure 5. Statistical visualization of mean values acquired based on Landsat imagery during the 30 years for the city of Mexico City. (a) Relationship between temperature and NDVI, (b) the relationship between temperature and NDBI and (c) the relationship between temperature and MNDWI.

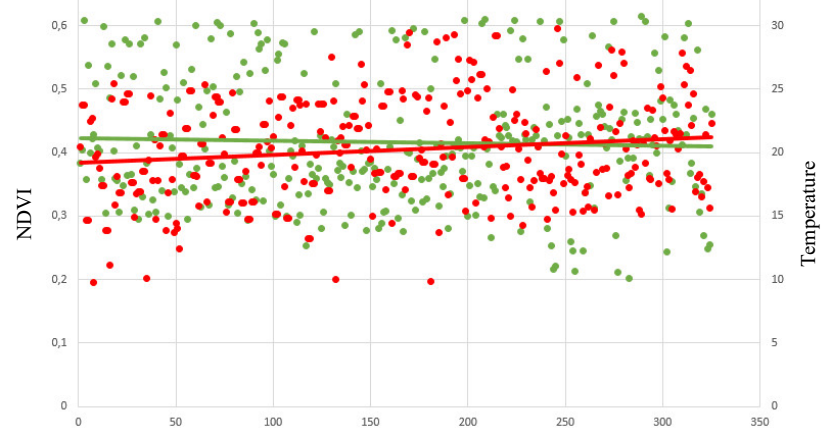

(a) 


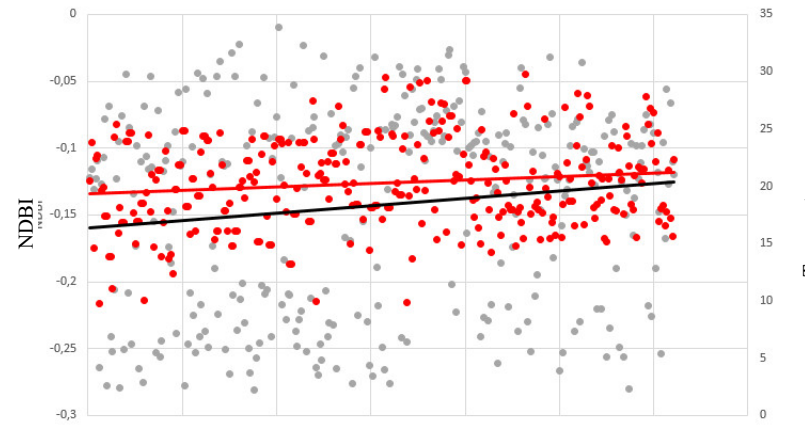

(b)

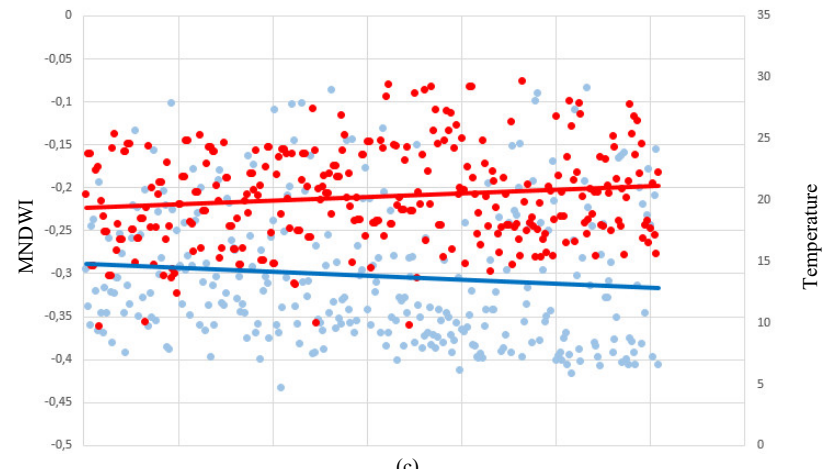

(c)

Figure 6. Statistical visualization of mean values acquired based on Landsat imagery during the 30 years for the city of Sao

Paulo. (a) Relationship between temperature and NDVI, (b) the relationship between temperature and NDBI and (c) the relationship between temperature and MNDWI.

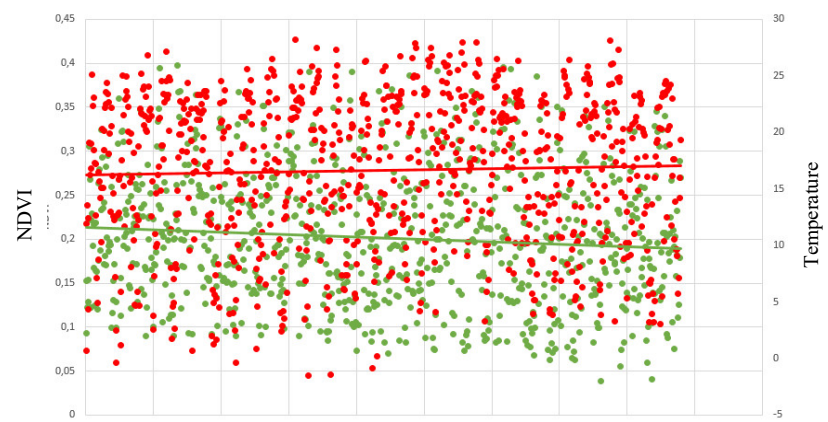

(a)

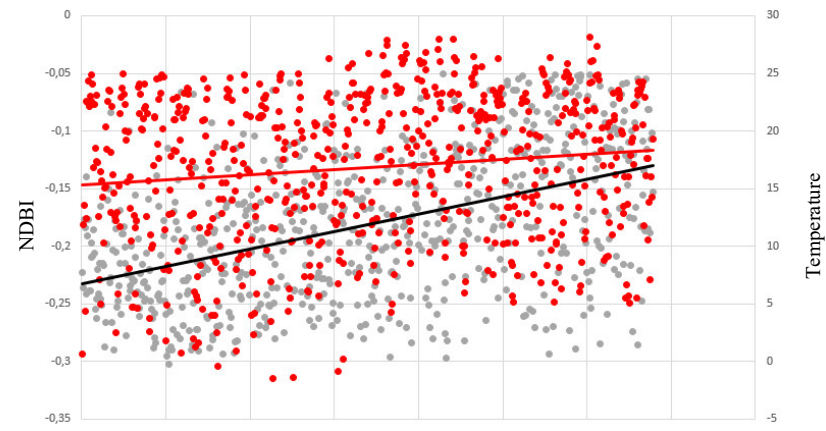

(b)

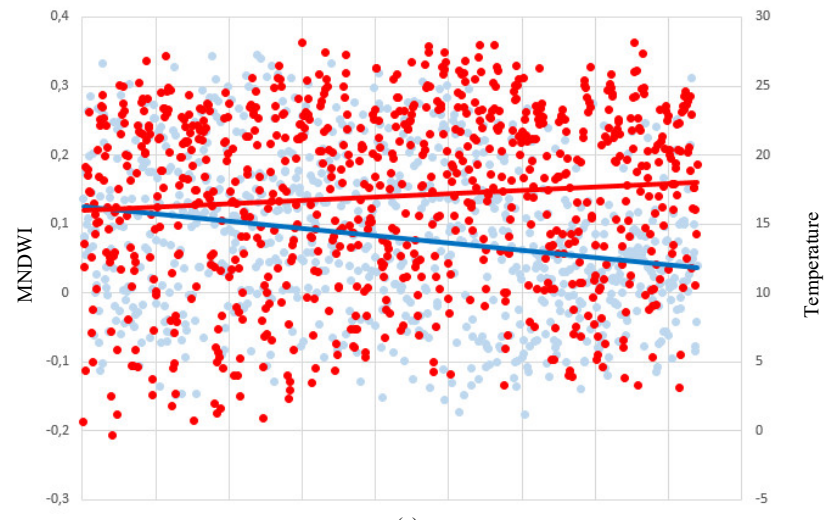

(c)

Figure 7. Statistical visualization of mean values acquired based on Landsat imagery during the 30 years for the city of Istanbul.

(a) Relationship between temperature and NDVI, (b) the

relationship between temperature and NDBI and (c) the relationship between temperature and MNDWI.

\section{CONCLUSIONS}

This research aimed to analyze the impact of urbanisation on the creation of thermal islands and trends in the period from 1990 to 2020 in five large cities based on satellite images obtained from Landsat satellite missions. Analyse was done by correlation of the three different spectral indices and LST. This research presents a simple methodology and solution for testing the urbanisation impact on creating heat islands in large cities. Furthermore, GEE was used and tested to provide all mandatory data for providing fast and optimal big data analysis.

The rates of change that have taken place in individual cities are different because no two cities are the same, not located in the same area and not subject to the same socio-economic processes at the same time. Examples of good urbanisation can be seen, for example, in the city of Tokyo, where it is visible according to the classification, but also the values of individual indices that urbanisation is carried out, but it is also visible that there is no significant change in NDVI, which would mean ecosystem conservation. Keeping in mind their water resources, they turned to the gradual transformation of a part of these water resources into an urban area that is later suitable for constructing roads. The city of Cairo is not such a good example of urbanisation where already scarce green and water areas are reduced, and the built-up area is drastically increased, which later leads to marked temperature changes in a negative sense and is reflected in one of the most significant temperature changes in thirty years.

In all five megalopolises (Cairo, Istanbul, Mexico City, Sao Paulo and Tokyo) located on five different continents, an increase in temperature in cities and consequently an increase in a built-up area, and a decrease in green and water areas was noticed. A great deal of attention will have to be paid in the coming years to reduce the temperature growth rate and enable ecosystem sustainability. Future studies of the presented methodology can be improved by using more spectral indices and tested on more megalopolises worldwide. 


\section{ACKNOWLEDGEMENTS}

The authors would like to thank the University of Zagreb, Croatia, that funded the project entitled: "Advanced photogrammetry and remote sensing methods for environmental change monitoring" (RS4ENVIRO), the Ministry of Science and Education, Croatia, for supporting space and space technology initiatives.

\section{REFERENCES}

Ahmed, H. A., Singh, S. K., Kumar, M., Maina, M. S., Dzwairo, R., Lal, D. 2020. Impact of urbanisation and land cover change on urban climate: Case study of Nigeria. Urban Climate, 32, 100600 .

Avdan, U., Jovanovska, G. 2016. Algorithm for automated mapping of land surface temperature using LANDSAT 8 satellite data. Journal of sensors, 2016, 1480307.

Chen, X. L., Zhao, H. M., Li, P. X., Yin, Z. Y. 2006. Remote sensing image-based analysis of the relationship between urban heat island and land use/cover changes. Remote sensing of environment, 104(2), 133-146.

Connolly, C., Keil, R., Ali, S. H. 2020. Extended urbanisation and the spatialities of infectious disease: Demographic change, infrastructure and governance. Urban Studies, 0042098020910873.

Gašparović, M. 2020. Urban growth pattern detection and analysis. In Urban Ecology (pp. 35-48). Elsevier.

Gašparović, M., Singh, S. K. (2020). Spatio-temporal salinity monitoring of the Ghaghara river using Landsat time-series imagery and multiple regression analysis. The International Archives of Photogrammetry, Remote Sensing and Spatial Information Sciences, 43, 401-405.

Gašparović, M., Zrinjski, M., Gudelj, M. 2017. Analysis of Urbanisation of Split. Geodetski list, 71(3), 189-202.

Gunawardena, K. R., Wells, M. J., Kershaw, T. 2017. Utilising green and bluespace to mitigate urban heat island intensity. Science of the Total Environment, 584, 1040-1055.

Kamali Maskooni, E., Hashemi, H., Berndtsson, R., Daneshkar Arasteh, P., Kazemi, M. 2021. Impact of spatiotemporal landuse and land-cover changes on surface urban heat islands in a semiarid region using Landsat data. International Journal of Digital Earth, 14(2), 250-270.

Kikon, N., Singh, P., Singh, S. K., Vyas, A. 2016. Assessment of urban heat islands (UHI) of Noida City, India using multitemporal satellite data. Sustainable Cities and Society, 22, 1928.

Li, L., Zha, Y. 2019. Satellite-based spatiotemporal trends of canopy urban heat islands and associated drivers in China's 32 major cities. Remote Sensing, 11(1), 102.

Oldenborgh, G. J. V., Philip, S., Kew, S., Weele, M. V., Uhe, P., Otto, F., Singh, R., Pai, I., Cullen, H., AchutaRao, K. 2018. Extreme heat in India and anthropogenic climate change. Natural Hazards and Earth System Sciences, 18(1), 365-381.
Rajasekar, U., Weng, Q. 2009. Urban heat island monitoring and analysis using a non-parametric model: A case study of Indianapolis. ISPRS Journal of Photogrammetry and Remote Sensing, 64(1), 86-96.

Renard, F., Alonso, L., Fitts, Y., Hadjiosif, A., Comby, J. 2019. Evaluation of the effect of urban redevelopment on surface urban heat islands. Remote Sensing, 11(3), 299. 